\title{
THERMAL STRATIFICATION IN A HOT WATER TANK ESTABLISHED BY HEAT LOSS FROM THE TANK
}

\author{
J. Fan and S. Furbo \\ Department of Civil Engineering, Technical University of Denmark, \\ Brovej, Building 118, DK-2800 Kgs. Lyngby, Denmark; email: jif@byg.dtu.dk
}

\begin{abstract}
Results of experimental and numerical investigations of thermal stratification and natural convection in a vertical cylindrical hot water tank during standby periods are presented. The transient fluid flow and heat transfer in the tank during cooling caused by heat loss are investigated by computational fluid dynamics (CFD) calculations and by thermal measurements. A tank with uniform temperatures and thermal stratification is studied. The distribution of the heat loss coefficient for the different parts of the tank is measured by tests and used as input to the CFD model. The investigations focus on the natural buoyancy resulting in downward flow along the tank side walls due to heat loss of the tank and the influence on thermal stratification of the tank by the downward flow and the corresponding upward flow in the central parts of the tank.

Water temperatures at different levels of the tank are measured and compared to CFD calculated temperatures.

The investigations will gain insight into the natural buoyancy driven flow in the tank. It is elucidated how thermal stratification in the tank is influenced by the natural convection and how the heat loss from the tank sides will be distributed at different levels of the tank for different thermal conditions.
\end{abstract}

\section{INTRODUCTION}

Thermal stratification in solar storage tanks has a major influence on the thermal performance of a solar heating system. A high degree of thermal stratification in the storage tank increases the thermal performance of solar heating system because the return temperature to the solar collector is lowered (van Koppen et al., 1979; Furbo and Mikkelsen, 1987; Hollands and Lightstone, 1989). A lower inlet temperature to the solar collector will increase the efficiency and operating hours of the solar collector. Further, the temperature at the top of the storage will be closer to the desired load temperature. Therefore the auxiliary energy consumption will be decreased which increases the solar fraction (Furbo and Knudsen, 2006 and Andersen and Furbo, 2007).

Heat loss from the tank helps to build up thermal stratification in the tank. Due to heat loss to the surroundings, the fluid close to the tank wall has a lower temperature than the fluid at the centre of the tank. The relative colder fluid flows downwards along the tank wall while the fluid with higher temperature rises up in the centre of the tank. The fluid flow and heat transfer in such a tank is dominated by transient, three dimensional, buoyancy driven flow. The flow and heat transfer phenomena inside an underground thermal storage tank naturally cooled down by heat loss was studied numerically by (Papanicolaou et al. 2004). A two-dimensional numerical model is used to solve the transient flow and thermal fields within the tank coupled with the heat transport through the tank walls and within the ground. Natural convection was found to dominate at the early transients when a strong recirculation develops, with a Rayleigh number characteristic of turbulent flow. A low-Re k- $\varepsilon$ turbulence model is used for the computation. As time proceeds and the temperature differences between water and surroundings decrease, the recirculation decays and the heat transfer is dominated by thermal diffusion. Comparisons are made under realistic conditions with preliminary experimental results showing satisfactory agreement.

This paper presents results of experimental and numerical investigations of thermal stratification and natural convection in a vertical cylindrical hot water tank during standby periods. The transient fluid flow and heat transfer in the tank during cooling caused by heat loss are investigated by computational fluid dynamics (CFD) calculations and by thermal measurements. A tank with uniform temperatures and thermal stratification is studied. The investigations focus on the natural buoyancy resulting in downward 
flow along the tank side walls due to heat loss of the tank and the influence on thermal stratification of the tank by the downward flow and the corresponding upward flow in the centre parts of the tank. The aim of the investigation is to gain insight into the natural buoyancy driven flow in the tank and to elucidate how thermal stratification in the tank is influenced by the natural convection and how the heat loss from the tank sides will be distributed at different levels of the tank for different thermal conditions.

\section{NUMERIC AND EXPERIMENTAL STUDIES}

The effect of heat loss on thermal stratification in a tank was investigated experimentally with a slim 152 1 tank with a diameter of $0.34 \mathrm{~m}$ and a height of $1.68 \mathrm{~m}$. The tank is made of steel and is insulated with 5 $\mathrm{cm}$ mineral wool. The heat loss coefficient from different parts of the tank is measured with the setup shown in Fig. 1. During the measurements, the tank is heated by an electric heating element to a uniform constant temperature. The heat loss from the tank is therefore equal to the power of the electric heating element. Measurement of the heat loss coefficient from different parts of the tank is possible with help of the iso-temperature box which is kept at the same temperature as the water temperature in the tank. Therefore there is no heat loss from the part of the tank which is covered by the box. By means of measurements with different positions of the box and with two temperature levels of $76.0^{\circ} \mathrm{C}$ and $36.5^{\circ} \mathrm{C}$, the distribution of the heat loss coefficient on the different parts of the tank is determined.

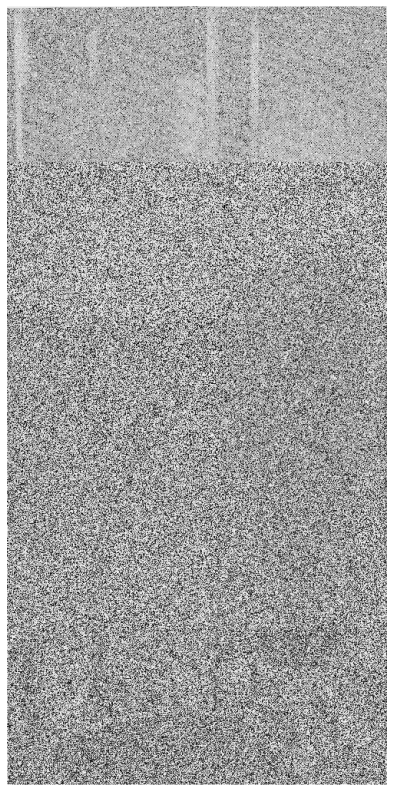

A. the Iso-temperature box and the tank

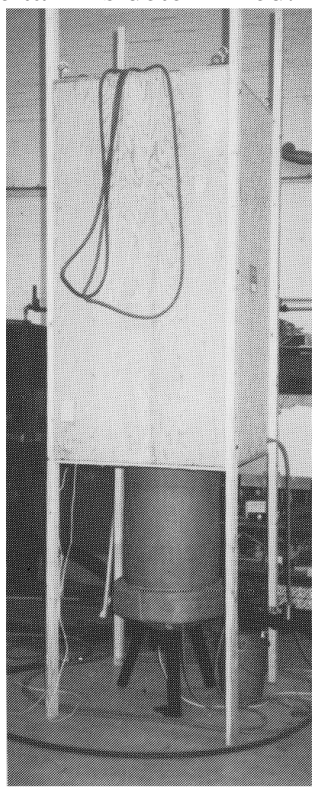

B. Measurement of tank heat loss coefficient

Figure 1. Experimental setup

CFD calculations are carried out to theoretically investigate the fluid flow in the hot water tank. A simplified hot water tank model with a tank diameter of $0.34 \mathrm{~m}$ and a height of $1.68 \mathrm{~m}$ is built using the CFD code Fluent 6.3, see Fig. 2. The mesh on the vertical cut-plane of the tank is shown in A. In order to better resolve the heat transfer and fluid flow in the region adjacent to the tank wall, a boundary layer mesh is applied so that there is a fine and dense mesh in the area close to the wall, see Fig. $2 \mathrm{~B}$ and $2 \mathrm{C}$. The 3D tank model includes the steel tank wall as a solid region and the hot water volume of the tank as a fluid region while the insulation materials are not directly modelled. The effect of the insulation materials is considered by the heat loss coefficients measured by the experiment. The heat loss coefficient of the tank are divided into three parts: heat loss coefficient of the top surface, of the side and of the bottom surface. The heat loss coefficients measured by the experiments are used as input to the model. The heat loss coefficients are finely tuned within the measurement inaccuracy so that the heat loss from the tank calculated by the CFD calculation is the same as the measured heat loss. The following equations are used to calculate heat loss coefficients of the tank:

$$
K_{\text {top }}=0.24+0.00015^{*} \mathrm{t} \quad[\mathrm{W} / \mathrm{K}]
$$




$$
\begin{array}{ll}
K_{\text {side }}=1.75+0.00148 * \mathrm{t} & {[\mathrm{W} / \mathrm{K}]} \\
K_{\text {bottom }}=0.41+0.00034 * \mathrm{t} & {[\mathrm{W} / \mathrm{K}]} \\
K_{\text {total }}=2.4+0.00198 * \mathrm{t} & {[\mathrm{W} / \mathrm{K}]}
\end{array}
$$

where $\mathrm{t}$ is the water temperature in the tank, $\left[{ }^{\circ} \mathrm{C}\right]$.

Mean average ambient air temperature during the experiment is used as the free stream temperature of the tank surfaces.

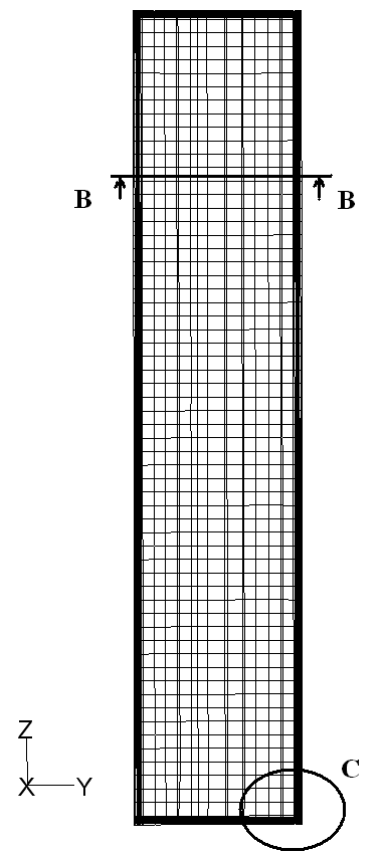

A. Vertical cut plane of the tank model

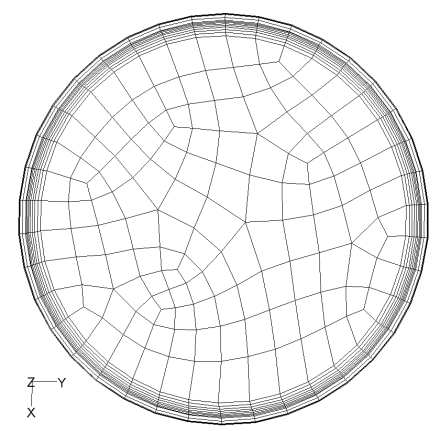

B. Cross section of the tank model

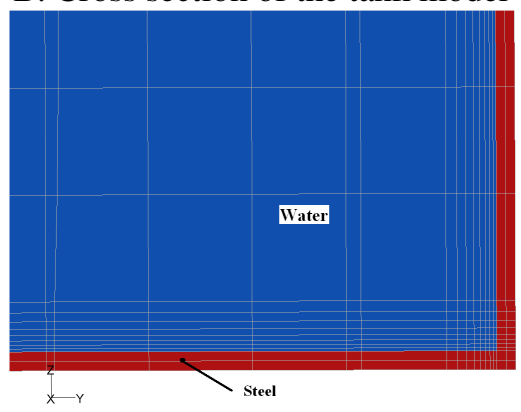

C. A magnified view of the corner

Figure 2. CFD model of the hot water tank

Water is used as the heat storage media. Properties of water and their dependences on temperature are shown as follows:

$$
\begin{array}{ll}
\text { Density, }\left[\mathrm{kg} / \mathrm{m}^{3}\right] & \rho=863+1.21 * \mathrm{~T}-0.00257 * \mathrm{~T}^{2} \\
\text { Dynamic viscosity, }[\mathrm{kg} /(\mathrm{ms})] & \mu=0.0007 *\left(\frac{T}{315}\right)^{-5.5}
\end{array}
$$

where $\mathrm{T}$ is fluid temperature, $[\mathrm{K}]$.

The tank wall material, steel, has a thermal conductivity of $60 \mathrm{~W} / \mathrm{K} / \mathrm{m}$ and a density of $7850 \mathrm{~kg} / \mathrm{m}^{3}$.

Calculation of Rayleigh number shows that the flow is in the laminar region, therefore a laminar model is used in the calculation. The mathematic equations representing physical laws of the fluid flow can be generalized by the following equation:

$$
\oint_{A} \rho \phi \mathbf{V} \cdot d \mathbf{A}=\oint_{A} \Gamma \nabla \phi \cdot d \mathbf{A}+\int_{V} S_{\phi} d V
$$

where $\oint_{A} \rho \phi \mathbf{V} \cdot d \mathbf{A}, \quad \oint_{A} \Gamma \nabla \phi \cdot d \mathbf{A}$ and $\int_{V} S_{\phi} d V$ stand for change of parameter $\phi$ due to convection, diffusion and generation respectively. $\rho$ and $\Gamma$ are density and diffusive coefficient respectively. V stands for velocity vectors. S is generation rate of $\phi$. A and V stand for area and volume of the control 
volume respectively. For $\phi$ as 1 , for velocities and for temperature, the generalized equation represents the continuum, the momentum and the energy equations, respectively.

Transient CFD calculations are performed with a density of water as a function of temperature, shown in equation (5). The PRESTO and second order upwind method are used for the discretization of the pressure and the momentum/energy equations respectively. The SIMPLE algorithm is used to treat the pressure-velocity coupling. The transient simulations start from either a tank with uniform temperature of $80^{\circ} \mathrm{C}$ or a stratified tank with $80^{\circ} \mathrm{C}$ at the top and $16.8^{\circ} \mathrm{C}$ at the bottom of the tank. A zero velocity field is assumed at the start of all simulations. The calculation is considered convergent if the scaled residual for the continuity equation, the momentum equations and the energy equation are less than $10^{-3}, 10^{-3}$ and $10^{-6}$ respectively. The simulation runs with a time step of 2-4 s and a duration of $24 \mathrm{~h}$. One simulation takes approximately 24-48 hours for a quad-core processor computer with 4 X $3 \mathrm{GHz}$ CPU frequency and 4G memory.

Investigations are carried out to detect the optimal time step and grid density. Time intervals in the range of 1-30 s are tried. The result shows that a time step in the range of 2-4 $\mathrm{s}$ is sufficient. Fig. 3 shows CFD calculated and measured temperatures of water in the centre of the tank 6 hours after the start of the test. The measurement was started with a uniform tank temperature of $80^{\circ} \mathrm{C}$. The temperature at different levels of the tank is measured continuously. It can be seen that Grid 1, with a cell size of $0.04 \mathrm{~m}$ and no boundary layer mesh, can predict well the water temperature at the top and the middle part of the tank. The inaccuracy of temperature prediction is within $0.5 \mathrm{~K}$. However at the bottom of the tank it tends to significantly overestimate water temperatures with an inaccuracy of 3-4 K. Grid 2 is created by applying a boundary layer mesh with 6 rows and a first row height of $0.001 \mathrm{~m}$ to the model of Grid 1 . The result of Grid 2 show a significant improvement of the accuracy of temperature prediction at the bottom of the tank. The difference between measured and CFD calculated temperatures is maximum $1.5 \mathrm{~K}$. The model is further improved with a decrease of cell size to $0.03 \mathrm{~m}, 0.02 \mathrm{~m}$ and $0.017 \mathrm{~m}$ and a decrease of first row height from $0.001 \mathrm{~m}$ to $0.0008 \mathrm{~m}$ and $0.0005 \mathrm{~m}$ respectively. However the increase of cell numbers has apparently no significant improvement on the prediction accuracy. It is therefore concluded that Grids 3-7 are grid independent. Grid 4 is used in the following calculations.

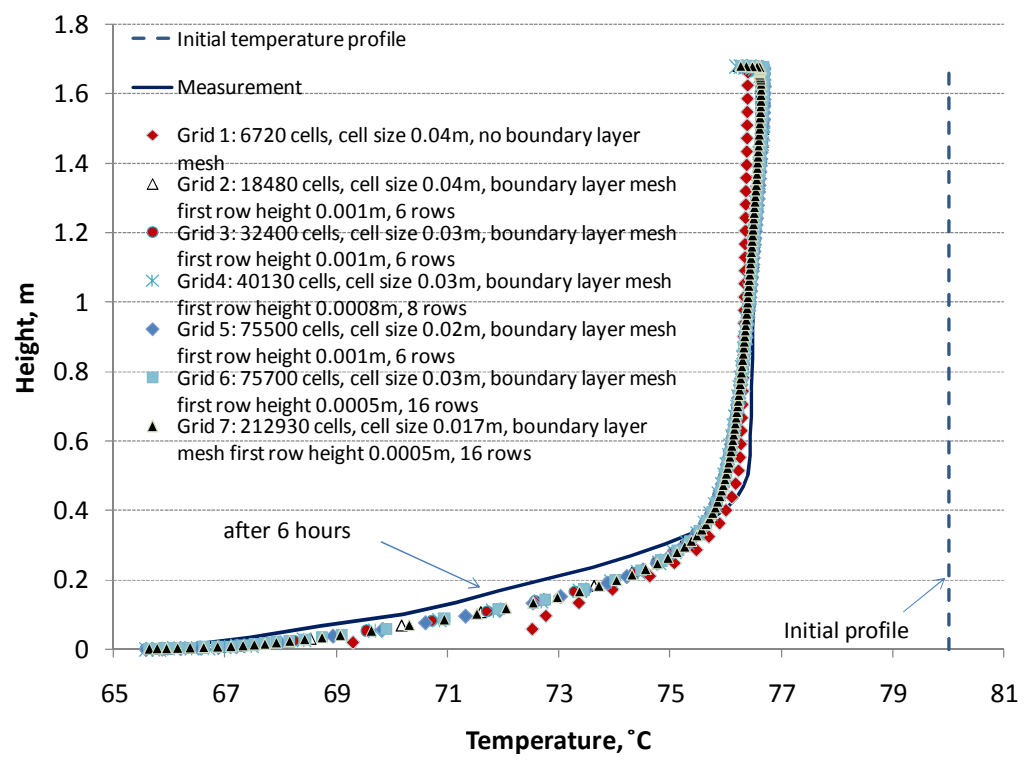

Figure 3. CFD calculated and measured temperatures of water in the tank 6 hours after the start

\section{RESULTS AND DISCUSSION}

\section{Thermal stratification}

Due to heat loss from the tank, the fluid close to the tank wall has a lower temperature than the fluid at the centre of the tank. The relative colder fluid close to the wall flows down along the wall while in the centre 
of the tank water with higher temperature rises up to a higher level, thus bringing the heat loss down to the lower part of the tank. Temperature distribution of water in the tank is investigated both experimentally and theoretically. Fig. 4 shows CFD calculated and measured temperatures of water in the tank at different times of the test. The measurements are started with a uniform tank temperature of $80^{\circ} \mathrm{C}$. The tank is cooled down by an ambient air temperature of $23.2^{\circ} \mathrm{C}$. After 1 hour, the water temperature at the top and the middle parts of the tank is uniformly $79.3^{\circ} \mathrm{C}$ while from tank height $0.3 \mathrm{~m}$ to the very bottom of the tank there is a gradual decrease of temperature from $79.3^{\circ} \mathrm{C}$ to $74.5^{\circ} \mathrm{C}$, corresponding to a maximum temperature difference of $4.8 \mathrm{~K}$ between the top and the bottom of the tank. After 6 hours, the bulk water temperature decreases to $76.5^{\circ} \mathrm{C}$ while water at the very bottom of the tank decreases to $65.6^{\circ} \mathrm{C}$. The temperature difference between tank top and tank bottom increases to $10.9 \mathrm{~K}$. At 24 hours after the start of the experiment, the water temperature at the top part of the tank decreases to $66.4^{\circ} \mathrm{C}$ while the water temperature at the bottom of the tank is decreased down to $52.7^{\circ} \mathrm{C}$. It can be seen that thermal stratification gradually builds up as the cold water flows downward along the tank wall, bringing heat loss down to the lower part of the tank.

The CFD calculated temperatures are compared to the measured water temperatures at the centre of the tank, see Fig. 4. The mean ambient temperature during the experiment is used as input to the CFD model. At 1 hour after the start, the CFD calculation predicts well the temperature in the tank except a slightly lower temperature (max. temperature difference $0.6 \mathrm{~K}$ ) at the middle of the tank. At 6 hours after the start, the CFD calculation give an underestimated temperature of max. $0.5 \mathrm{~K}$ at the middle of the tank but an overestimated temperature at the bottom of the tank (max. $1.6 \mathrm{~K}$ ). At 12 hours, the CFD slightly the overestimate energy content of the tank. At 24 hours, the CFD calculation again predicts an underestimated temperature at the upper part and an overestimated temperature at the bottom of the tank with max. inaccuracy of $2.3 \mathrm{~K}$. The difference between the CFD calculation and the measurement can be explained by variations of the ambient air temperature during the measurement. In the CFD model, the mean ambient air temperature is used as the free stream temperature of the tank surfaces, which is constant during the calculation. The ambient temperature, in reality, is varying within 1-2 $\mathrm{K}$ during the experiment. A higher than average ambient air temperature will give a lower heat loss from the tank, thus a overestimated energy content of the tank. Another reason for the overestimation at the bottom of the tank is due to contraction of the water during cooling. Cold water enters the bottom of the tank with a lower temperature at the bottom as a result, because the tank is user the pressure from the mains, The contraction is not considered in the CFD calculations. All in all, the comparison between CFD calculated and measured temperatures shows that the CFD model predicts well water temperatures in the tank.

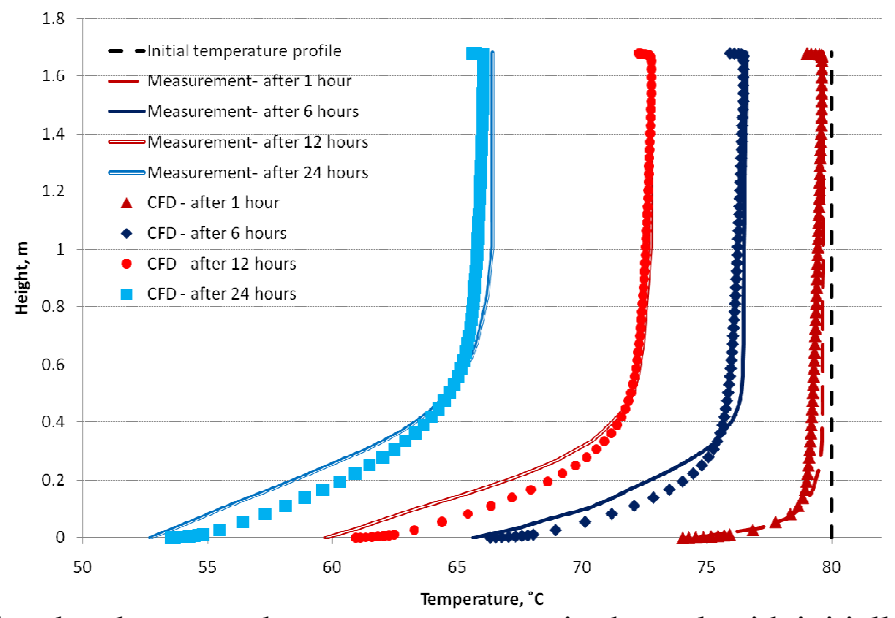

Figure 4. CFD calculated and measured water temperatures in the tank with initially uniform temperature.

The validity of the CFD model for an initially stratified tank is investigated as well. The results are shown in Fig. 5. A stratified tank is achieved by a draw-off from a tank with a uniform temperature of $80^{\circ} \mathrm{C}$ and followed by a standby period of 2 minutes. The tank is left to be cooled down with an ambient air temperature of $22.5^{\circ} \mathrm{C}$. The initial temperature profile at the start of the measurement is shown in Fig. 5 . The temperature profile is used as initial conditions of the CFD calculation by means of User Defined 
Function. It can be seen that the CFD model predicts well the water temperature at different times of the test. The maximum prediction inaccuracy is $1 \mathrm{~K}$ at the bottom of the tank after 24 hours. It can be concluded that the CFD model is validated.

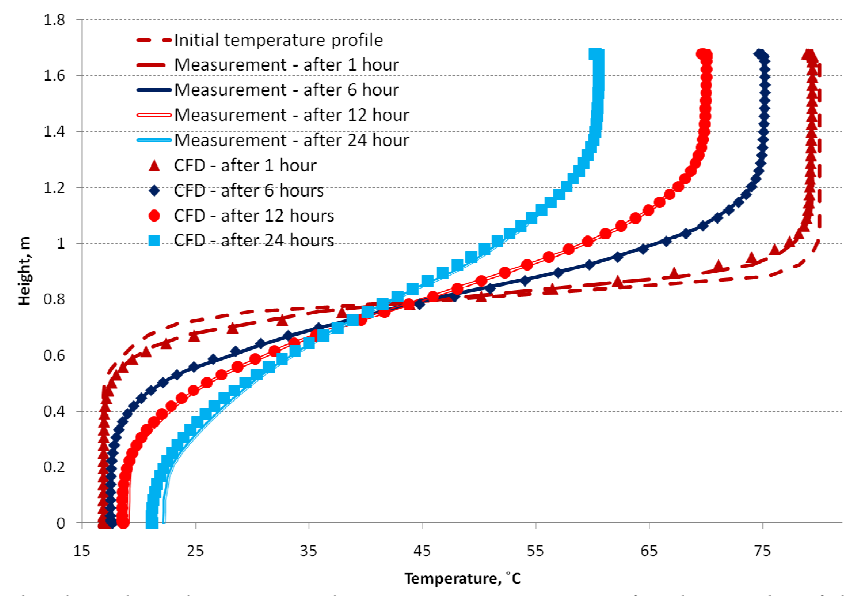

Figure 5. CFD calculated and measured water temperatures in the tank with initially stratified temperatures.

\section{Buoyancy driven flow}

The buoyancy driven flow in the tank due to heat loss from the tank is investigated by CFD calculations. The temperature profile of the tank were examined at 12 hours after the start of a standby period for the tank with a uniform temperature of $80^{\circ} \mathrm{C}$, see Fig. 6. From Fig. 6A it can be seen that the water temperature is almost the same from $1 \mathrm{~m}$ height to the top of the tank. There is a slight temperature decrease of temperature $(0.4 \mathrm{~K})$ from $1 \mathrm{~m}$ to $0.56 \mathrm{~m}$ tank height. At the lower part of the tank a strong thermal stratification exists with a temperature decrease of $11.2 \mathrm{~K}$ from $0.56 \mathrm{~m}$ to the bottom of the tank. The CFD calculated temperatures and vertical fluid velocities at different heights of the tank are shown in Fig. 6B. At the height of $1.58 \mathrm{~m}(0.1 \mathrm{~m}$ from the top of the tank $)$, the fluid temperature is approx. $72.5^{\circ} \mathrm{C}$ in the area close to the tank wall while it is approx. $72.7^{\circ} \mathrm{C}$ in the central part of the tank. Due to the relative lower temperature of the fluid close to the wall, there is a downward flow with a vertical fluid velocity of up to $0.005 \mathrm{~m} / \mathrm{s}$. In the bulk of the tank, there is two flow circulation which brings fluid of lower temperature downwards and fluid of higher temperature upwards. The strong flow circulation is caused by the heat loss from the top of the tank. At 2/3 tank height $(1.12 \mathrm{~m})$, the fluid temperature drops to $72.4^{\circ} \mathrm{C}$ in the boundaries and $72.6^{\circ} \mathrm{C}$ in the rest of the tank. In the area close to the tank wall the fluid flows downwards with a velocity slightly higher than the fluid at the height of $1.58 \mathrm{~m}$. At $1 / 3$ of the tank height, the downward flow slows down with a velocity of $0.002 \mathrm{~m} / \mathrm{s}$ due to the presence of thermal stratification. In the middle of the tank there is an upward flow of $0-0.0005 \mathrm{~m} / \mathrm{s}$ meaning that the warm fluid rises up.

Figure 7 shows how the vertical fluid velocity at $1.12 \mathrm{~m}$ from the tank bottom develop as the tank is cooled down. It can be seen that the max. downward flow is $0.009 \mathrm{~m} / \mathrm{s}$ at 1 hour after the start. The buoyancy driven flow gradually decreases to $0.004 \mathrm{~m} / \mathrm{s}$. This can be explained by decreased temperature and increased thermal stratification of the tank.

The buoyancy driven flow in a stratified tank is investigated as well. Fig. 8A shows the temperature profile in the tank at 3 hour after the start. At the upper part of the tank there is a uniform temperature of $77.7^{\circ} \mathrm{C}$ while the water temperature at the bottom of the tank is almost constant at $17^{\circ} \mathrm{C}$. In the middle part of the tank there is a strong thermal stratification with an increase of $59 \mathrm{~K}$ from $0.5 \mathrm{~m}$ to $1.2 \mathrm{~m}$ of the tank. From Fig. 8B, it can be seen that there is a downward flow of up to $0.005 \mathrm{~m} / \mathrm{s}$ along the tank wall at the height of $1.58 \mathrm{~m}$ due to the absence of stratification. It is also noticed that water in the central parts of the tank is flowing downwards and upwards due to the heat loss from the top of the tank. At the height of $1.12 \mathrm{~m}$, there is very weak downward flow although the water temperature is only $3 \mathrm{~K}$ lower than the 
water temperature at $1.58 \mathrm{~m}$ of the tank, which can be explained by the presence of strong stratification at the middle of the tank. At $0.56 \mathrm{~m}$ height, there is a weak upward flow close to the tank wall. The rising flow has the magnitude of approx. $0.0004 \mathrm{~m} / \mathrm{s}$. This can be explained by a negative heat loss of the tank which heats up the fluid adjacent to the wall, creating upward flow.

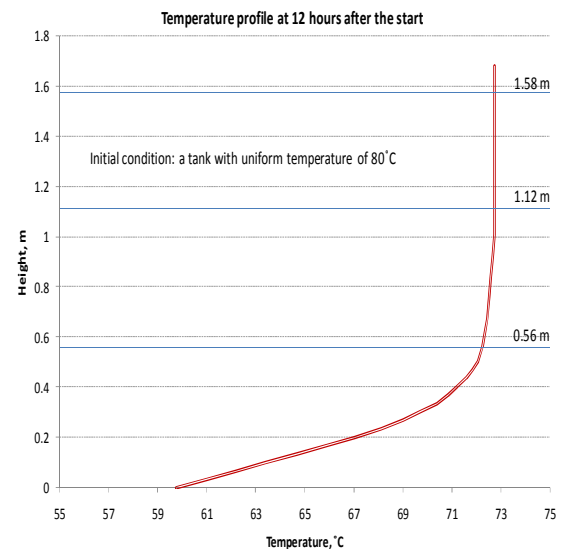

A. Temperature profile in the tank

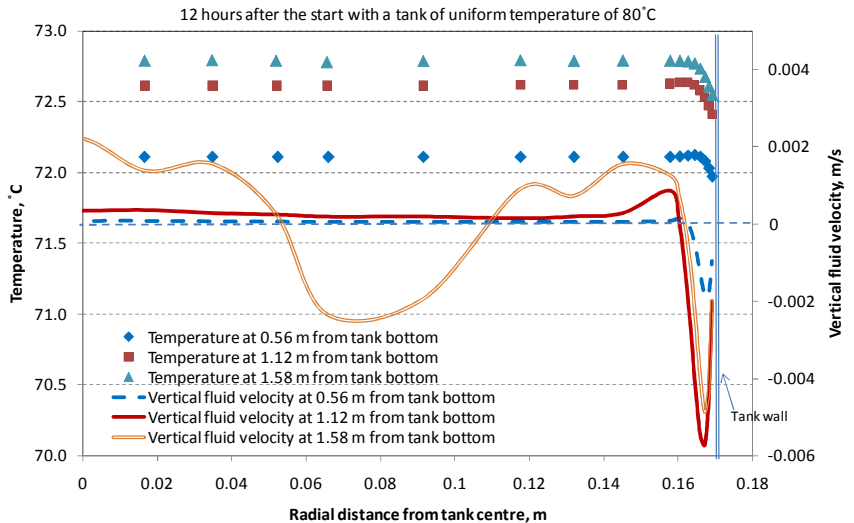

B. CFD calculated temperatures and velocities

Figure 6. CFD calculated temperatures and vertical fluid velocities at different heights.

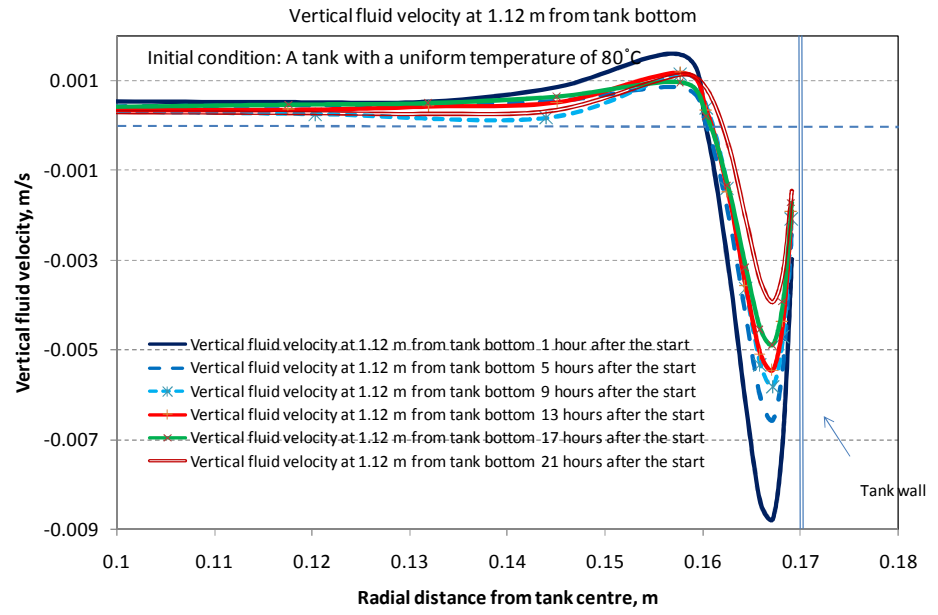

Figure 7. CFD calculated vertical fluid velocity at different times

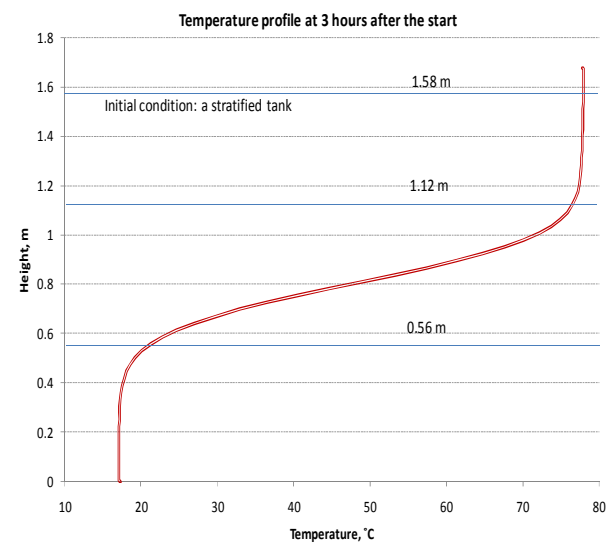

A. Temperature profile in the tank

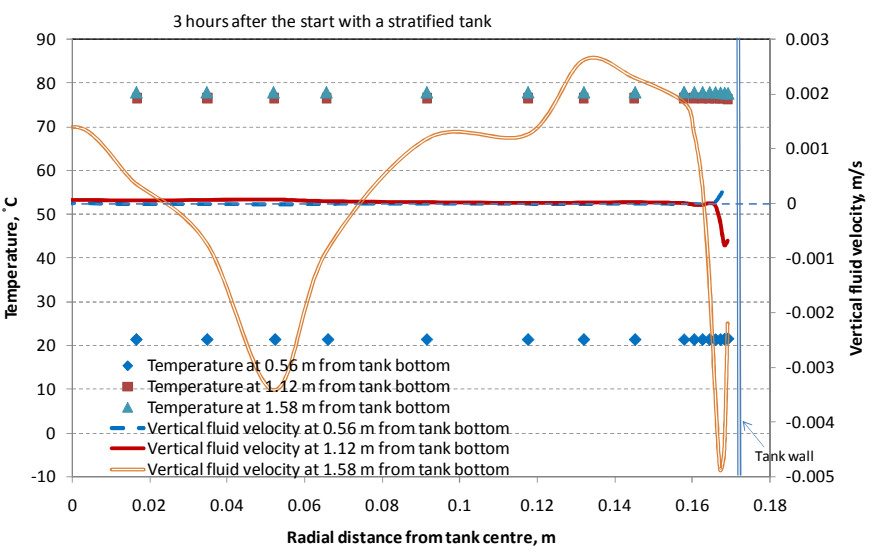

B. CFD calculated temperatures and velocities Figure 8. CFD calculated temperatures and vertical fluid velocities at different heights of the tank. 


\section{HEAT LOSS REMOVAL FACTOR}

In order to analyze the magnitude of the buoyancy driven flow and the influence of the flow on the thermal stratifications, the tank is equally divided into a number of layers $(\mathrm{N}=10)$, numbered sequentially from the bottom to the top of the tank, see Fig. 9. Heat loss from the side of the layer I is defined as $\mathrm{Q}_{\text {loss }}(\mathrm{I})$ calculated based on traditional heat transfer theory while the heat loss moving from the layer above (I+1) to the layer (I) due to the buoyancy driven flow is defined as $\mathrm{Q}_{\text {flow }}(\mathrm{I})$. A heat loss removal factor $a(I)$ for surface $I$ is defined as the ratio between the heat loss moved down by natural convection and the total amount of heat loss of the layer. The heat loss of the layer includes both heat loss from the side of the tank and the heat loss moved down from the layer above.

$$
a(I)=\frac{Q_{\text {flow }}(I)}{Q_{\text {flow }}(I+1)+Q_{\text {loss }}(I+1)}
$$

For the top layer $\mathrm{N}$, the heat loss moving from the layer above is replaced by the heat loss from the top of the tank.

$$
a(N-1)=\frac{Q_{\text {flow }}(N-1)}{Q_{\text {heat loss from the top }}+Q_{\text {loss }}(N)}
$$

Thermal stratification in the tank is characterized by a temperature gradient $\mathrm{Gr}(\mathrm{I})$.

$$
G r(I)=\frac{T_{\text {Layer }}(I+1)-T_{\text {Layer }}(I)}{H_{\text {Layer }}(I+1)-H_{\text {Layer }}(I)}
$$

where $T_{\text {Layer }}(\mathrm{I})$ is the average fluid temperature of layer $\mathrm{I}$ in $\mathrm{K}$, while $\mathrm{H}_{\text {Layer }}$ (I) is the average height of layer I in m measured from the bottom of the tank.

The heat loss removal factor $a(I)$ is calculated for all the 9 inter-layer surfaces and shown in Fig. 10 for a cooling test starting with a uniform tank temperature of $80^{\circ} \mathrm{C}$. At 3 hours after the start, the temperature gradient, $\mathrm{Gr}(\mathrm{I})$ is very small for the most part of the tank, $0.2-0.9 \mathrm{~K} / \mathrm{m}$ for the upper 7 inter-layer surfaces, showing that there is almost no thermal stratification at the middle and upper parts of the tank. At the lower part of the tank the temperature gradient, $\mathrm{Gr}(\mathrm{I})$ increases to $2.4 \mathrm{~K} / \mathrm{m}$ and $16 \mathrm{~K} / \mathrm{m}$ for the second and the first surface respectively, indicating thermal stratification at the lower part of the tank. The heat removal factor is greatly influenced by the temperature gradient at small values. $a(I)$ is approx. 0.55, meaning that $55 \%$ of the apparent heat loss of the layer placed above the surface in question plus the heat loss transferred from the upper parts of the tank to the layer placed above the surface is transferred down to the layer below the surface. At the lower part of the tank, the heat loss removal factor drops to 0.16 and 0.08 for the second and the first surface respectively. It is the thermal stratification in the lower part of the tank that stops the cooled water from flowing downwards. The heat loss removal factor is calculated for different time steps and is shown in Fig. 10. A tendency can be observed that the heat loss removal factor goes to a lower level at the lower part of the tank as the time goes. That is due to the gradual cooling down of the tank and due to the thermal stratification established at the lower part of the tank.

The heat exchange between layers by means of natural convection is shown in Fig11. At the upper part of the tank, the heat exchange between the layers is in the range of 4-16 W. As long as there is no thermal stratification, the heat transferred upwards is equal to or higher than the calculated heat loss from one layer (6-10.4 $\mathrm{W}$ from $1 / 10$ of the tank side), while at the lower part of the tank the heat exchange is significantly reduced to a value smaller than $1 \mathrm{~W}$.

The heat exchange between layers for a stratified tank is given in Fig. 12. A heat exchange of 4-11 W can be observed at the upper part of the tank. The heat exchange decrease dramatically at the middle part of the tank when the temperature gradient increases from 10 to up to $130 \mathrm{~K} / \mathrm{m}$. The strong thermal stratification suppresses the buoyancy driven flow and therefore reduces the heat exchange by natural convection to a value lower than $1 \mathrm{~W}$. The heat exchange is in the range of $[-0.15,0.15] \mathrm{W}$ at the lower part of the tank which could be due to disturbed flow of the water. 


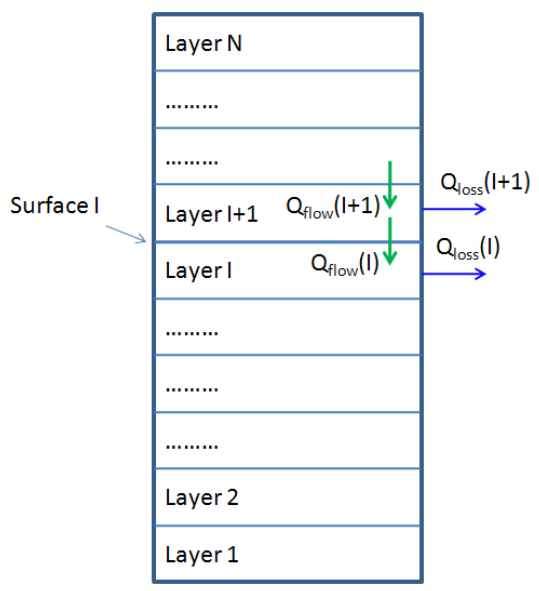

Figure 9. Schematic illustration of a tank consisting of $\mathrm{N}$ layers.

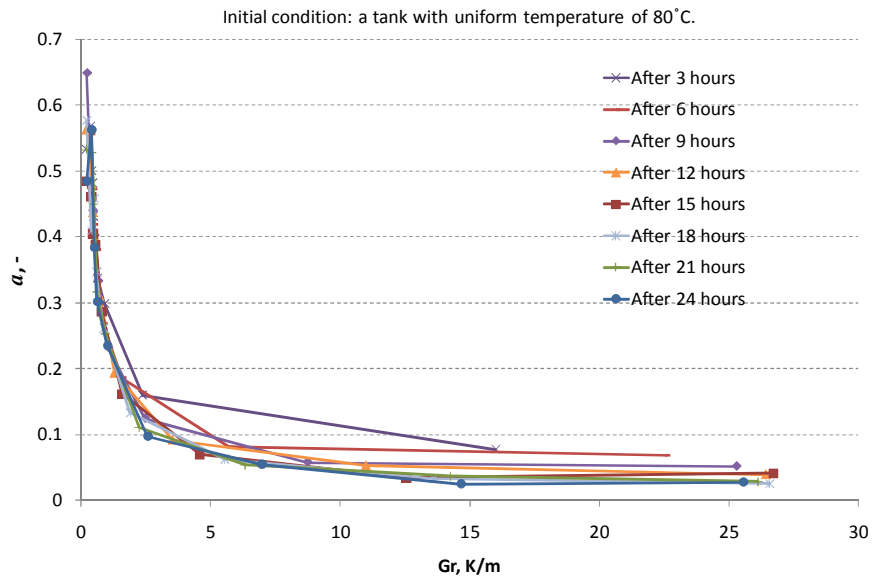

Fig. 10 The influence of stratification on heat loss removal factor for a cooling test starting with a uniform temperature of $80^{\circ} \mathrm{C}$.

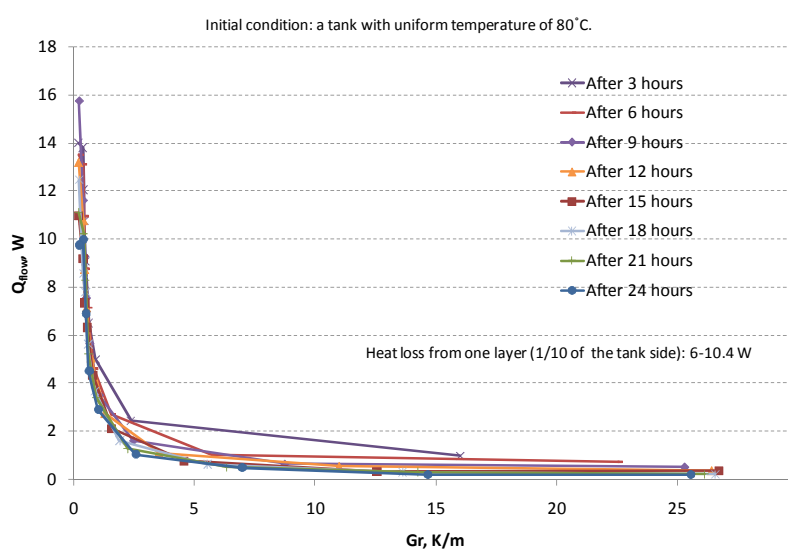

Figure 11. The heat exchange between layers versus temperature gradient in the tank for a cooling test starting with a uniform temperature of $80^{\circ} \mathrm{C}$.

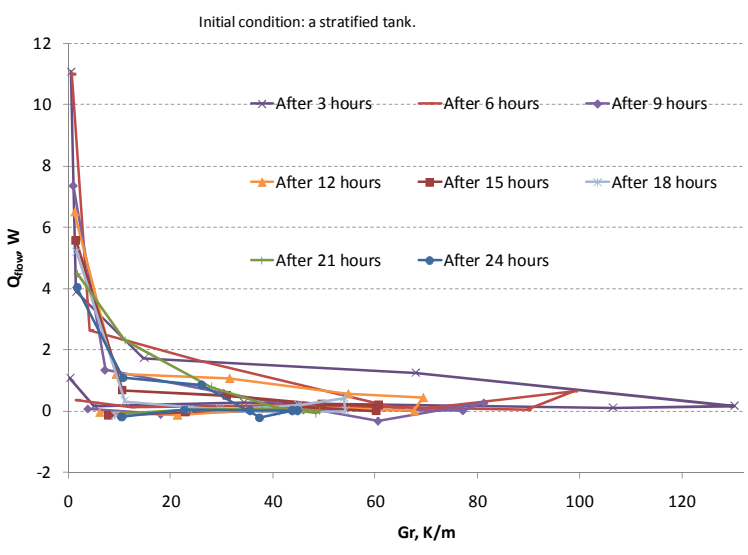

Figure 12. The heat exchange between layers versus temperature gradient in the tank for a cooling test starting with a stratified tank.

The heat loss removal factor is calculated for all the surfaces at different time steps with a heat exchange higher than $1 \mathrm{~W}$ to obtain a good accuracy. The heat removal factor is shown in Fig. 13. Also for the stratified tank the tendence is clear: The lower the temperature gradient, the higher the heat loss removal factor.

The calculations for the tank with a uniform tank and for the stratified tank are summarized in Fig. 14. A regression analysis is then performed which gives a best fit of the points by the equation (12). The Rsquared value of the regression is 0.91 . It is expected that the equation can later be implemented in an easy to use simulation program which calculates thermal performance of a hot water tank.

$a(I)=0.25 G r^{-0.60}$

\section{CONCLUSIONS AND OUTLOOK}

By means of CFD calculations and thermal experiments, thermal stratification in a vertical cylindrical hot water tank during cooling caused by heat loss is investigated. A tank with a uniform temperature and with thermal stratification is studied. Water temperatures at different levels of the tank are measured and compared to CFD calculated temperatures. The results show that the CFD calculation predicts satisfactorily the water temperature in the tank during cooling of the tank. 


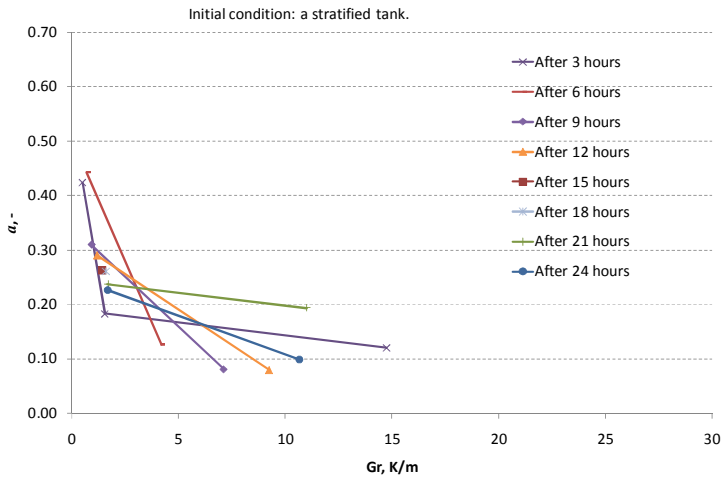

Fig. 13 The influence of stratification on heat loss removal factor for a cooling test starting with a stratified tank.

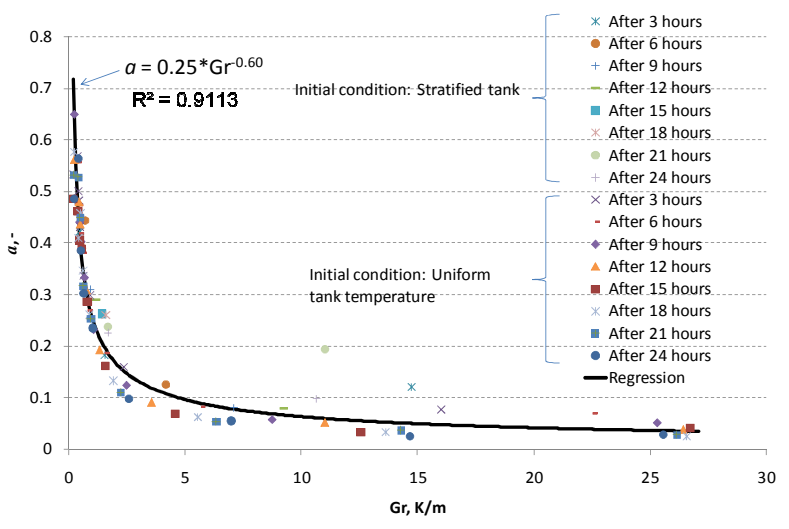

Fig. 14 The heat loss removal factor.

It is shown that without the presence of a strong thermal stratification there is a buoyancy driven flow along the tank side walls due to heat loss of the tank and a corresponding upward flow in the centre parts of the tank. A heat loss removal factor is used to characterize the effect of the buoyancy driven flow on the heat exchange between layers by natural convection. It is observed that $20 \%-55 \%$ of the side heat loss drops to layers below if the temperature gradient is in the range of $0.2-1.5 \mathrm{~K} / \mathrm{m}$ which means that the heat loss from the tank helps to build up thermal stratification in the tank. With the presence of thermal stratification the buoyancy driven flow is signification reduced. A simple equation is obtained by regression which calculates the heat loss removal factor for a given temperature gradient. In the future further investigations will be carried out to determine the influence of tank height to diameter ratio, tank volume and tank insulation on the thermal stratification built up by heat loss from the tank. The ultimate goal is to find an equation or equations which can be implemented in an existing tank optimization and design program for calculation of thermal performance of a hot water tank.

\section{REFERENCES}

Andersen, E. and Furbo, S, (2007) "Theoretical comparison of solar water/space heating combi systems and stratification design options", Journal of Solar Energy Engineering, 129, 438-448.

Furbo, S. and Knudsen, S. (2006) "Improved design of mantle tanks for small low flow SDHW systems", International Journal of Energy Research, 30, 955-965.

Furbo, S., and Mikkelsen, S. E. (1987) "Is low flow operation an advantage for solar heating systems?" Proceedings of the ISES Solar World Congress, 1987, Hamburg, Germany, Bloss, W. H. and Pfisterer, F., Advances in Solar Energy Technology, vol. 1, Pergamon Press, Oxford, 962-966.

Hollands, K. G. T. and Lightstone, M. F. (1989) "A review of low-flow stratified-tank solar water heating system" Solar Energy, 43, 97-105.

Papanicolaou, E. and Belessiotis, V. (2004) "Phenomena and Conjugate Heat Transfer During Cooling of Water in an Underground Thermal Storage Tank", Journal of Heat Transfer, 126, 84-96.

van Koppen, C.W.J., Thomas, J.P.X. and Veltkamp, W.B. (1979) "The actual benefits of thermally stratified storage in a small and medium size solar systems", Proceedings of the ISES Solar World Congress, 1979, Atlanta, USA, 579-580. 